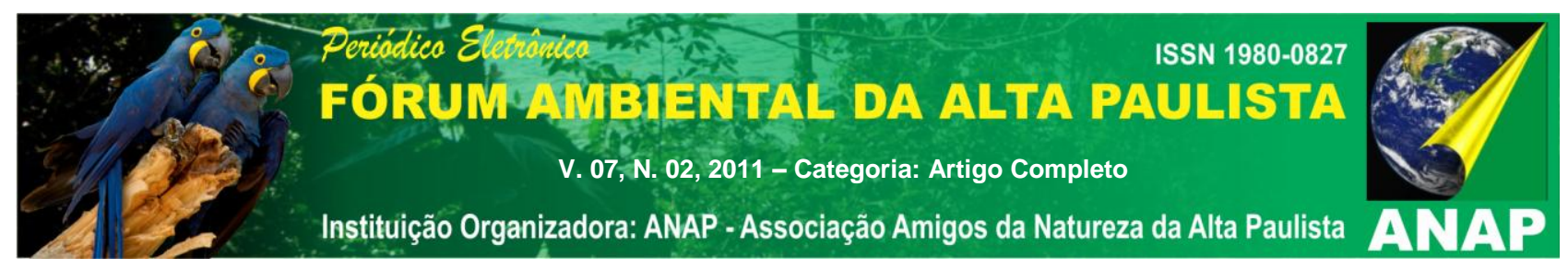

\title{
QUALIDADE E LIMITAÇÕES DE USO DA ÁGUA SUPERFICIAL DA LAGOA MAIOR, TRÊS LAGOAS/MS
}

\section{Denivaldo Ferreira de Souza ${ }^{1}$}

\section{André Luiz Pinto²}

Resumo: O Conselho Nacional do Meio Ambiente - CONAMA normatizou através das resoluções 357 de 2005 e 396 de 2008, o enquadramento das limitações de uso de corpos hídricos perante os padrões de qualidade. A água não deve somente ser considerada um bem natural indispensável à sobrevivência dos seres vivos, mas, pelo seu valor político, econômico e social. Perante a importância da água para a sociedade e que segundo Tundisi (2003) pode ser qualificada pelos cuidados que tem por suas águas, o presente trabalho analisou a qualidade da maior lagoa urbana da cidade de Três Lagoas, que constitui o seu principal atrativo turístico, segundo os parâmetros de oxigênio dissolvido, ph, turbidez, condutividade elétrica, temperaturas do ar e da água. Parâmetros estes, de fácil realização no campo, baixo custo e que possibilita informações passíveis de enquadramento nas classes da resolução de corpos hídricos superficiais doces. Para tanto, foram coletadas amostras em treze estações ao redor da Lagoa Maior, os quais localizam-se em pontos estratégicos, tais como: saídas de caixas de retenção de água pluvial, afloramento de água subterrânea e ladrões de controle de nível da água da lagoa. Os resultados enquadram a lagoa, em sua maioria, na classe IV, que preconiza seu uso apenas para navegação e à harmonia paisagística.

Palavras-chave: Qualidade e Limitações; Uso da Água; Lagoa Maior.

\section{INTRODUÇÃO}

Ao longo da evolução dos seres vivos, o homem sofreu uma metamorfose física e intelectual, juntamente com essas mudanças existiu uma variação do bem mais precioso para a vida em sociedade, a água. Nos primórdios o fogo era fundamental para sobrevivência em tribos, passando pelo metal, carvão, petróleo e chegando ao presente, 


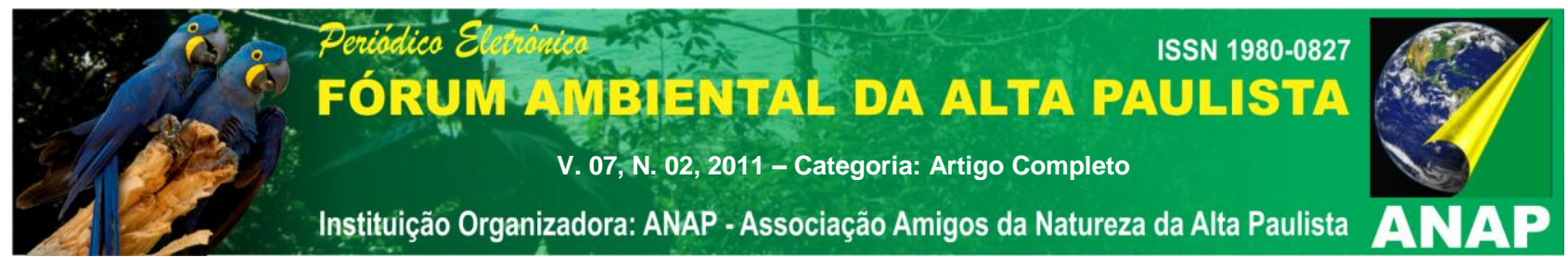

sendo a água o bem mais precioso nesse início de século XXI. A palavra "água" possui númeras definições, porém são poucas que esclarecem de forma sucinta a sua real participação como recurso hídrico:

O Termo água refere-se, de modo geral ao elemento químico natural, desvinculado de qualquer uso ou utilização. Por sua vez, o termo recurso hídrico é a consideração da água como bem econômico, passível de utilização com tal fim. Entretanto, deve-se ressaltar que toda água não é, necessariamente, um recurso hídrico, na medida em que seu uso ou utilização nem sempre tem viabilidade econômica. (REBOUÇAS, 2004).

Contudo, a água pode ser considerada um recurso abundante, relativamente para as necessidades atuais. No passado era visto como bem infinito impossível de acabar, mas os tempos mudaram e a água é hoje o recurso mais importante para vida, e é caracterizado como finito para o consumo humano. Moitta e Cudo (1991) relatam que a escassez é muito mais grave em regiões onde o desenvolvimento se processou de forma desordenada. Isso é visto nos grandes centros urbanos onde a contaminação das águas disponíveis para o consumo acontece pelos lançamentos indiscriminados de esgotos domésticos, despejos industriais, agrotóxicos e outros poluentes.

A qualidade das águas está relacionada com interferências antrópicas nos recursos hídricos e com a disponibilidade de água, e o seu estudo é fundamental para a avaliação das possibilidades de uso. Para Tundisi (1999), alterações na qualidade, distribuição e quantidade de água podem ameaçar a sobrevivência dos seres vivos. E, com certas análises podemos classificar a adequação das águas para o consumo humano, recreação, indústria e agricultura.

No entanto, neste trabalho o objetivo destas análises é avaliar a qualidade e as sua limitações de uso da água superficial da lagoa urbana, conhecida como Lagoa Maior, na cidade de Três Lagoas/ MS, que no passado abasteceu a cidade e constitui o seu principal atrativo turístico, utilizando-se como indicador principal o oxigênio dissolvido OD e os parâmetros coadjuvantes de turbidez, temperatura da água e do ar, ph e condutividade elétrica. Parâmetros estes de fácil coleta e de baixo custo, possibilitando informações freqüentes, passíveis de enquadrar a Lagoa nas classes de limitações de uso do CONAMA, resolução 357 de 2005. Assim, o presente artigo destaca a análise da qualidade da água da Lagoa Maior, visando subsidiar ações e/ou estudos que visem contribuir para o ordenamento e gestão desse importante recurso hídrico de Três Lagoas. 


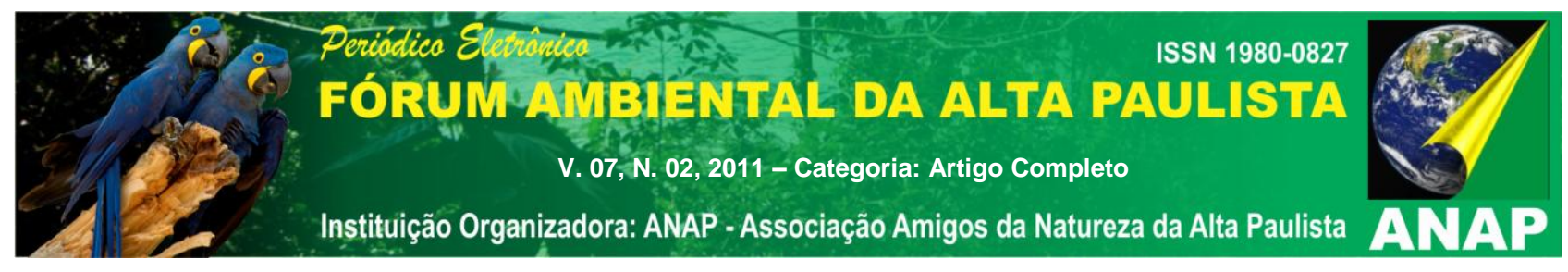

\section{METODOLOGIA}

A Lagoa Maior Urbana de Três Lagoas localiza-se na área central da cidade e corresponde a um dos pontos topograficamente mais baixo no perímetro urbano. $O$ entorno da Lagoa é ocupado por áreas de recreações como pista de caminhada, academias ao ar livre, campos de futebol, pista de skate, quadras de vôlei, e entre outras. Há também aos arredores vários comércios, em especial bares e restaurantes, e também algumas residências de alto padrão pelo fato da região ser economicamente bem valorizada.

Para Bollmann et. al. (2005), a urbanização altera o meio ambiente natural e um dos procedimentos que mais influência o mesmo é a impermeabilização do solo, pois afeta principalmente, de modo quantitativo e qualitativo, os recursos hídricos. Portanto, o emprego de indicadores de qualidade de água consiste no uso de variáveis que se correlacionam com as alterações ocorridas na bacia, sejam estas de origens antrópicas ou naturais.

Os parâmetros analisados consistem em:

O oxigênio dissolvido - OD é um gás solúvel em água, com concentrações recomendáveis pelo CONAMA Resolução 357 de 17/03/05. Tchobanoglous e Schroeder (1985) afirmam que, devido à sua importância, o OD é amplamente utilizado como principal parâmetro da qualidade de água e serve para determinar o impacto de poluentes sobre corpos d'água, pois é um dos mais importantes fatores no desenvolvimento de qualquer planejamento na gestão de recursos hídricos. Obviamente, o oxigênio dissolvido é o elemento principal no metabolismo dos microrganismos aeróbicos que habitam as águas naturais ou os reatores para tratamento biológico de esgotos, nas águas naturais, o oxigênio é indispensável também para os seres vivos, principalmente os peixes. $E$, cabe salientar que águas poluídas são aquelas que apresentam baixa concentração de O.D.

A condutividade elétrica - CE expressa à capacidade de condução de corrente elétrica de sais dissolvidos e ionizados presentes na água, pode ser utilizada como parâmetro de avaliação de qualidade. Assim a condutividade também fornece uma boa indicação das modificações na composição da água, especialmente na sua concentração 


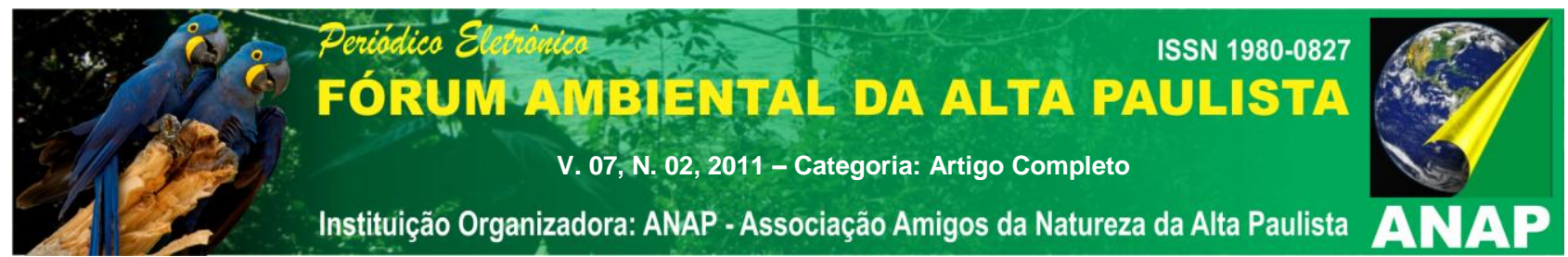

mineral, mas não fornece nenhuma indicação das quantidades relativas dos vários componentes.

A turbidez para Pinto (1998) é a alteração da penetração da luz provocada por partículas em suspensão, como bactérias, argilas e silte ou fontes de poluição que lançam materiais finos e outras substâncias na água. Certamente, a presença dessas substâncias provoca a dispersão e a absorção da luz, dando à água aparência nebulosa, esteticamente indesejável e potencialmente perigosa. Enfim, um alto valor de turbidez prejudica criando uma barreira sobre a água, reduzindo a fotossíntese da vegetação enraizada submersa e das algas. Esse desenvolvimento reduzido pode suprimir a produtividade de peixes, além disso, afeta adversamente os usos doméstico, industrial e recreacional da água; estudos técnicos constatam o efeito de proteção física de microorganismos pelas partículas causadoras da turbidez, diminuindo a eficiência de tratamentos.

O PH, potencial hidrogeniônico, é a medida de concentração de íons $\mathrm{H}+$ presentes na solução, é uma das determinações de qualidade de água mais frequentemente executadas, apresentando a acidez ou a basicidade das águas, que podem ter origens em fatores naturais do terreno ou resultantes de poluentes dissolvidos na água. A escala de ph é constituída de uma série de números variando de 0 a 14, os quais denotam vários graus de acidez ou alcalinidade. Valores abaixo de 7 e próximos de zero indicam aumento de acidez, enquanto valores de 7 a 14 indicam aumento da basicidade. $A$ análise do ph será feita através do método eletrométrico (CETESB, 1987).

Com relação às diferentes temperaturas, elas podem gerar camadas d'água com várias densidades, que em si já formam uma barreira física, impedindo que se misturem, e se a energia do vento não for suficiente para misturá-las, o calor não se distribui uniformemente, criando a condição de estabilidade térmica. Quando ocorre este fenômeno, o ecossistema aquático está estratificado termicamente. Os estratos formados freqüentemente estão diferenciados físico, químico e biologicamente. Para Silveira (2004) a temperatura da água é um fator importante na regulação das características físicas e bióticas dos riachos. E, certamente lagos, lagoas e lagunas se assemelham a essa definição. 


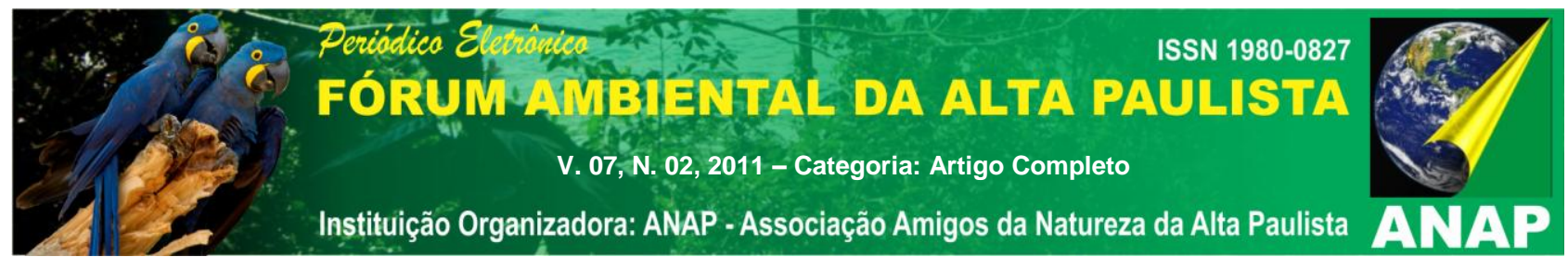

Para a mensuração dos parâmetros para a aferição da qualidade das águas superficiais da Lagoa Maior de Três Lagoas, foram utilizados os equipamentos e métodos abaixo relacionados, no Quadro 01.

\begin{tabular}{|l|l|l|}
\hline Parâmetros & Equipamentos & Método \\
\hline Oxigênio Dissolvido OD & Lutron DO-510 & Espectrofotomérico \\
\hline Condutividade & Tecnopon MCA - 150 & Eletrométrico \\
\hline Turbidez & Tecnopon TB 1000 & Eletrométriœ \\
\hline pH & Phtek pH - 100 & Eletrométriळ \\
\hline Temperatura & Lutron DO - 5510 & Eletrométriœ \\
\hline
\end{tabular}

Quadro 01 - Parâmetros, Equipamentos e Métodos Utilizados para Análise da Qualidade das Águas Superficiais da Lagoa Urbana Maior de Três Lagoas/MS

Para a análise utilizou-se a resolução 357 do Conselho Nacional do Meio Ambiente de 2005, que cria classes de enquadramento e de limitações de uso para os corpos hídricos superficiais para o Brasil, Tabela 01 e Quadro 02.

Tabela 01- Limites dos Parâmetros Analisados para Enquadramento nas Classes das Águas Doces no Brasil.

\begin{tabular}{|c|c|}
\hline Classes & Limites para o Enquadramento \\
\hline Especial & $\begin{array}{l}\text { Nas águas de classe especial deverão ser mantidas as condições } \\
\text { naturais do corpo de água. } \\
\text { OD }+10,0 \mathrm{mg} / \mathrm{l} \\
\text { pH } 6,0 \text { a } 9,0 \\
\text { Turbidez até } 40 \text { NTU } \\
\text { Condutividade Elétrica até } 50 \text { um }\end{array}$ \\
\hline I & $\begin{array}{l}\text { OD } 10 \text { a } 6 \mathrm{mg} / \mathrm{l} \\
\text { pH } 6,0 \text { a } 9,0 \\
\text { Turbidez até } 40 \text { NTU } \\
\text { Condutividade Elétrica } 50 \text { até } 75 \text { um }\end{array}$ \\
\hline II & $\begin{array}{l}\text { OD } 6 \text { a } 5 \mathrm{mg} / \mathrm{l} \\
\text { pH } 6,0 \text { a } 9,0 \\
\text { Turbidez } 40 \text { até } 100 \mathrm{NTU} \\
\text { Condutividade Elétrica } 75 \text { até } 100 \mathrm{um}\end{array}$ \\
\hline III & $\begin{array}{l}\text { OD } 5 \text { a } 4 \mathrm{mg} / \mathrm{l} \\
\text { pH } 6,0 \text { a } 9,0 \\
\text { Turbidez até } 100 \text { NTU } \\
\text { Condutividade Elétrica } 100 \text { até } 150 \text { um }\end{array}$ \\
\hline IV & $\begin{array}{l}\text { OD - } 4 \mathrm{mg} / \mathrm{l} \\
\text { pH } 6,0 \text { a } 9,0 \\
\text { Turbidez acima de } 100 \mathrm{NTU} \\
\text { Condutividade Elétrica }+150 \mathrm{um}\end{array}$ \\
\hline
\end{tabular}




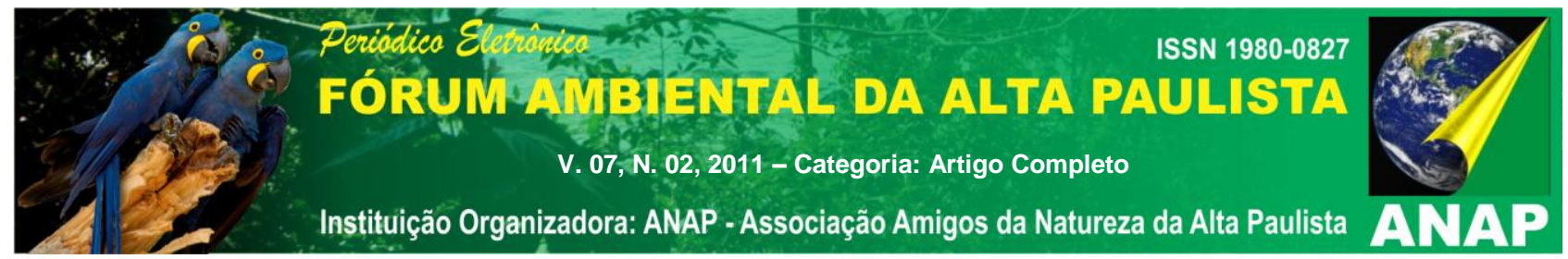

Fonte: Adaptação efetuada por Pinto et. al. (2008) da Resolução n. 357 do CONAMA de 17/03/2005.

\begin{tabular}{|l|l|}
\hline Classes & Principais Usos \\
\hline Especial & $\begin{array}{l}\text { Consumo humano com desinfecção; Preservação de equilíbrio natural das } \\
\text { comunidades aquáticas; Preservação dos ambientes aquáticos em unidades de } \\
\text { conservação de proteção integral. }\end{array}$ \\
\hline I & $\begin{array}{l}\text { Consumo humano, após tratamento simplificado; Proteção das comunidades } \\
\text { aquáticas; Recreação de contato primário (natação, esqui aquático e mergulho) } \\
\text { Resolução CONAMA n. 274, de 2000; Irrigação de hortaliças que são consumidas } \\
\text { cruas e de frutas que se desenvolvam rentes ao solo e que sejam ingeridas sem } \\
\text { remoção de películas e à proteção das comunidades aquáticas em Terras Indígenas. }\end{array}$ \\
\hline II & $\begin{array}{l}\text { Abastecimento para consumo humano, após tratamento convencional, à proteção das } \\
\text { comunidades aquáticas, à recreação de contato primário, tais como natação, esqui } \\
\text { aquático e mergulho, Resolução ConAMA n. 274, de 2000, à irrigação de hortaliças, } \\
\text { plantas frutíferas e de parques, jardins, campos de esporte e lazer, com os quais o } \\
\text { público possa vir a ter contato direto e à aqüicultura e à atividade de pesca. }\end{array}$ \\
\hline III & $\begin{array}{l}\text { Abastecimento para consumo humano, após tratamento convencional ou avançado, à } \\
\text { irrigação de culturas arbóreas, cerealíferas e forrageiras, à pesca amadora, à } \\
\text { recreação de contato secundário e à dessedentação de animais. }\end{array}$ \\
\hline IV & \begin{tabular}{l} 
Navegação e à harmonia paisagística \\
\hline
\end{tabular} \\
\hline
\end{tabular}

Quadro 02 - Classificação das águas doces brasileiras, segundo seus usos preponderantes, de acordo com a Resolução do CONAMA n. 357/2005.

Para a avaliação da qualidade das águas superficiais, foram escolhidas 13 estações de coletas, localizadas em pontos estratégicos ao arredor da Lagoa Maior. Os locais escolhidos são afloramento de água subterrânea, interior de caixas de retenções e suas respectivas saídas. Assim sendo, iniciou-se a atividade de campo com coletas realizadas do dia 12 de Agosto de 2011, marcada pela presença de sol e temperaturas variando de $17^{\circ} \mathrm{C}$ à 29으.

Estações amostradas: estação 1 (E1) corresponde a uma caixa de retenção de águas pluviais ao lado de uma academia ao ar livre para a população; a estação 2 (E2) é a saída da caixa anterior para dentro da lagoa; a estação 3 (E3) trata-se de uma entrada da água escoada da Lagoa do Meio e que acabou sendo fechada pelo alto índice de poluição da mesma, lembrando que no perímetro urbano o município possui três lagoas, ainda nesse mesmo local encontra-se um afloramento de água subterrânea; a estação 4 


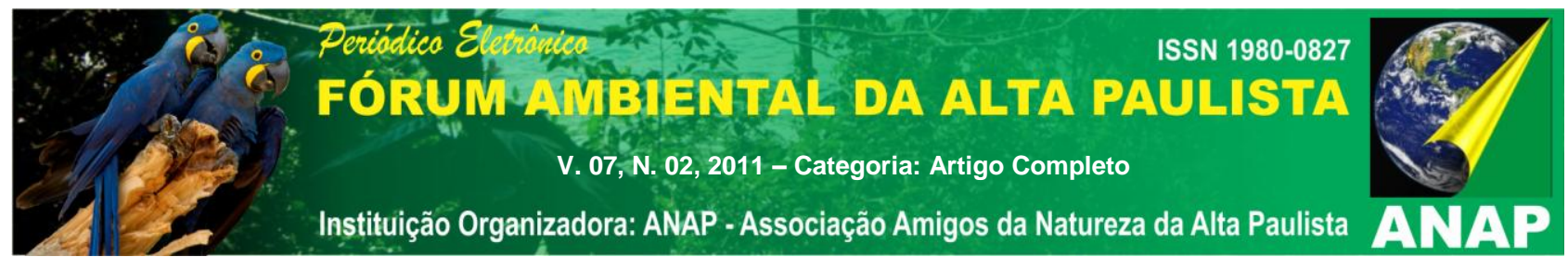

(E4) corresponde a outra caixa de retenção em frente a um bar conceituado na cidade e ponto de alagamento em períodos chuvosos; a estação 5 (E5) é a saída da caixa de retenção anterior; a estação 6 (E6) é mais uma caixa de retenção em frente a um hotel de alto padrão; a estação 7 (E7) é a saída da caixa de retenção anterior; a estação 8 (E8) é mais uma saída de caixa de retenção localizada em região bem arborizada; a estação 9 (E9) encontra-se dentro de uma caixa nas proximidades de um ponto de encontro de jovens; a estação 10 (E10) corresponde ao ponto topograficamente menos elevado e é o trecho que é escoado a água da Lagoa para o Córrego da Onça, o mais importante rio que corta a cidade; a estação 11 (E11) é uma galeria de entrada da água pluvial; a estação 12 (E12), um ponto muito visitado pela população, é um aterro onde encontra-se aves como patos e gansos que aceitam a presença humana que agradam-lhes com variados alimentos; e a estação 13 (E13) é mais uma entrada de caixa de retenção bem plana e ainda com alta presença de aves e pessoas.

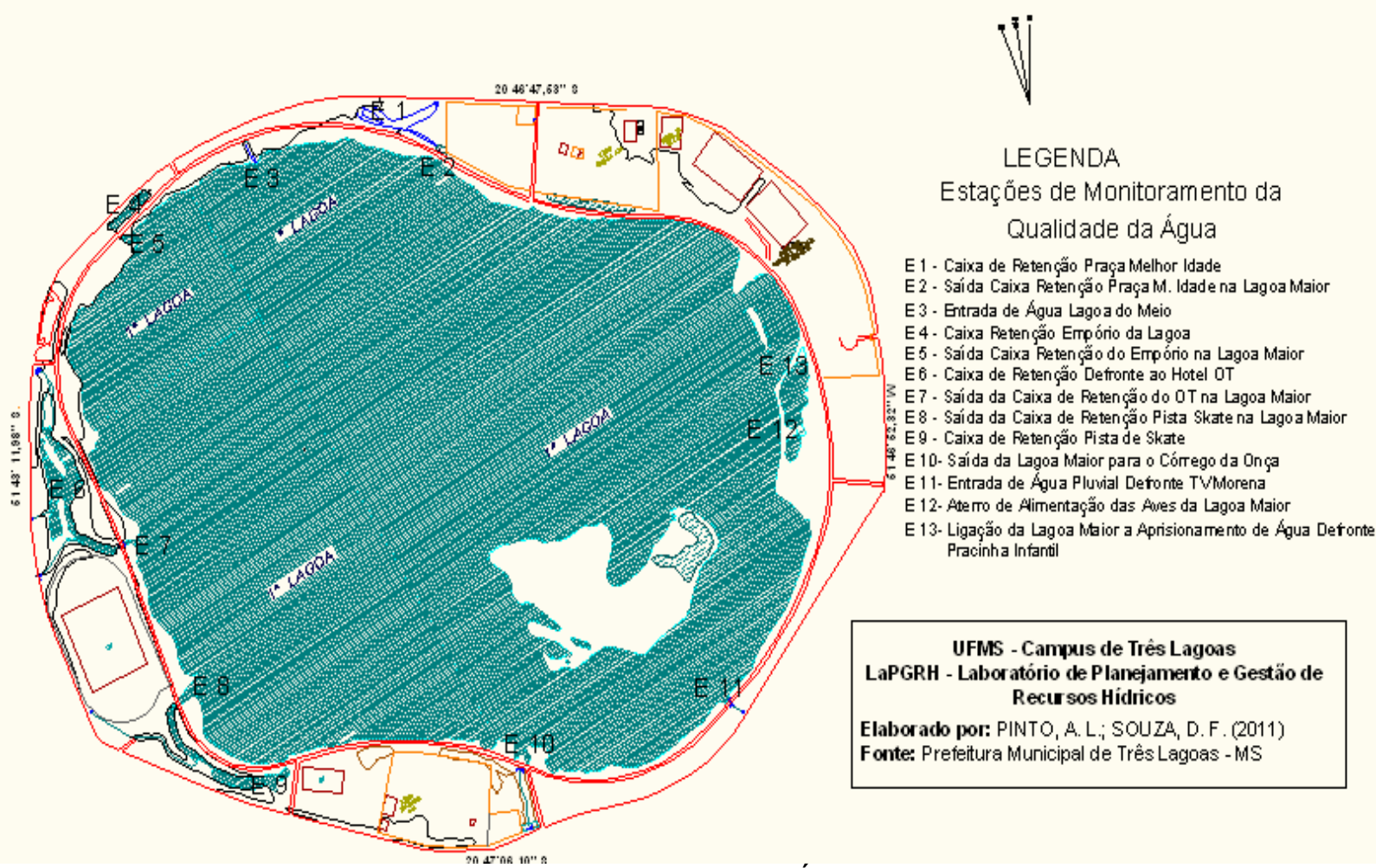

Figura 01- Estações de Monitoramento da Qualidade das Águas Superficiais da Lagoa Maior, Três Lagoas/MS

\section{RESULTADOS E DISCUSSÕES}




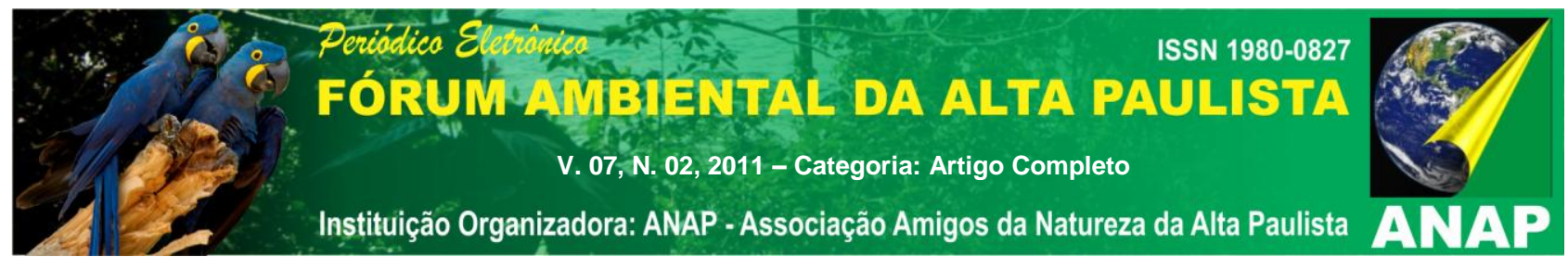

Utilizando os aparelhos específicos para a coleta, foram obtidos os seguintes resultados demonstrados na Tabela 02.

Tabela 02 - Resultados dos Parâmetros Físicos e Químicos Monitorados no mês de Agosto de 2011, na Lagoa Urbana Maior de Três Lagoas/MS

\begin{tabular}{c|c|c|c|c|c|c|c}
\hline Pontos & Horário & $\begin{array}{c}\text { Cond. } \\
\text { Elétrica } \\
(\mathbf{u m})\end{array}$ & $\begin{array}{c}\text { O. D. } \\
(\mathbf{m g} / \mathbf{l})\end{array}$ & $\begin{array}{c}\text { Temp. do } \\
\mathbf{A r} \\
\left.\mathbf{(}{ }^{\circ} \mathbf{C}\right)\end{array}$ & $\begin{array}{c}\text { Temp. da } \\
\text { H2O } \\
\left({ }^{\circ} \mathbf{C}\right)\end{array}$ & Ph & $\begin{array}{c}\text { Turbidez } \\
\text { NTU }\end{array}$ \\
\hline 1 & $07: 36$ & 199,50 & 0,70 & 20,1 & 19,1 & 7,80 & 50,40 \\
\hline 2 & $07: 50$ & 87,00 & 2,90 & 20,7 & 22,0 & 8,20 & 5,36 \\
\hline 3 & $07: 58$ & 198,50 & 2,80 & 20,3 & 20,4 & 7,70 & 14,40 \\
\hline 4 & $08: 06$ & 176,00 & 2,50 & 21,1 & 20,8 & 7,80 & 53,50 \\
\hline 5 & $08: 11$ & 112,00 & 2,90 & 21,3 & 22,1 & 7,80 & 24,90 \\
\hline 6 & $08: 31$ & 151,00 & 5,00 & 23,5 & 21,1 & 7,80 & 47,40 \\
\hline 7 & $08: 45$ & 144,00 & 7,60 & 20,7 & 22,0 & 7,90 & 48,70 \\
\hline 8 & $08: 50$ & 99,00 & 7,80 & 21,5 & 23,5 & 7,90 & 6,66 \\
\hline 9 & $09: 00$ & 389,00 & 7,70 & 22,5 & 22,7 & 7,90 & 122,00 \\
\hline 10 & $09: 08$ & 93,00 & 5,40 & 24,6 & 23,8 & 8,30 & 3,41 \\
\hline 11 & $09: 23$ & 87,00 & 6,80 & 24,1 & 24,5 & 8,30 & 2,31 \\
\hline 12 & $09: 30$ & 88,00 & 8,30 & 24,0 & 26,0 & 8,30 & 4,37 \\
\hline 13 & $09: 38$ & 82,00 & 7,10 & 24,9 & 25,1 & 8,40 & 8,34 \\
\hline
\end{tabular}

O Oxigênio dissolvido é o parâmetro principal para avaliar as condições naturais da água superficial e detectar possíveis impactos ambientais em corpos hídricos. Os resultados obtidos na Lagoa Maior enquadraram as estações 7, 8, 9, 11, 12 e 13 na classe I do CONAMA. Entretanto, as estações 2, 3, 4, 5 e principalmente a estação 1 com 0,70 mg/l ficaram todas na classe IV, a pior possível, sendo apenas recomendado para navegação e harmonia paisagística.

A condutividade elétrica nas estações 2, 8, 10, 11, 12 e 13 posicionou-se entre 75 a 100 microsimens - um, portanto enquadraram-se na classe especial II. As estações 5 e 7 registraram valores entre 100 à 150um, enquadrando-se na classe III que já habilita o ser humano a um contato secundário com a Lagoa. As estações 1, 3, 4, 6 e absurdamente a 9 com incríveis 389um ficarão na classe IV, onde recomenda-se apenas sua utilização para a "navegação e à harmonia paisagística". A razão mais provável deste elevado valor reside na migração de plumas de contaminação de antigas fossas e/ou devido à oxidação da água rica em sólidos ferrosos, que aliado aos sais de sódio das fossas aumenta a condutividade dessas águas. 


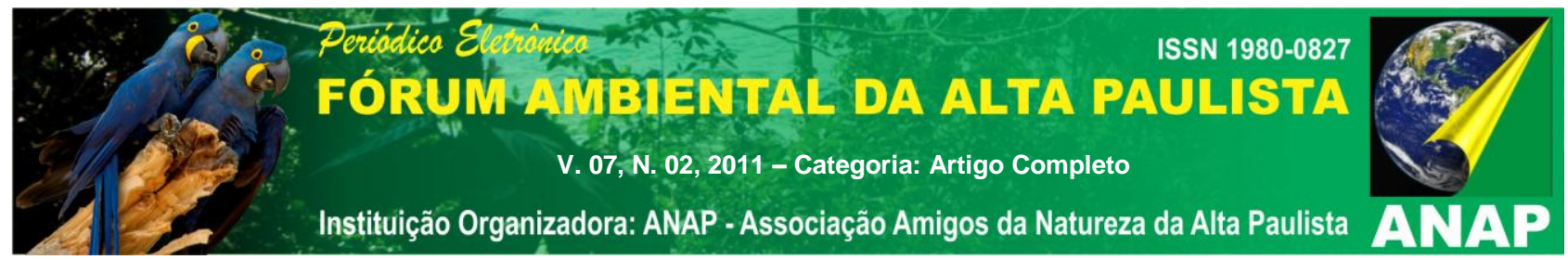

O ph, parâmetro que indica acidez ou a basicidade da água, em todas as estações se sobrepôs tolerante, indicando níveis de 6 a 9, recomendado pela resolução CONAMA 357, não causando riscos ao homem ou a vida aquática da lagoa. O ponto com maior destaque foi à estação 13, com o ph de 8,40, valor próximo ao limite máximo aceitável, enfim, um pouco mais de acidez poderia prejudicar a vida aquática levando a mortalidade de peixes e plantas.

A turbidez das águas superficiais da Lagoa Maior, parâmetro que indica a agitação de partículas que pode alterar a penetração de luz na água, podendo ser classificada como fontes de poluição comprometendo a estética da água ou contribuir escondendo bactérias e elementos químicos em laminolas de argilas. Através das análises laboratoriais, percebeu que nas estações 2, 3, 5, 8, 10, 11, 12 e 13 os valores oscilaram entre 0 a 40 NTU, posicionando-se na classe especial ou 1, as estações 1, 4, 6 e 7 entre 40 a 70 NTU, enquadrando-se na classe II e a estação 9, com 122 NTU, ficou na classe IV.

A temperatura se manteve na normalidade aquática aceitável para o dia, que correspondia a um dia de sol de inverno. A variação foi de $20^{\circ} \mathrm{C}$ à $25^{\circ \mathrm{C}}$ no ar e $19^{\circ} \mathrm{C}$ à $26^{\circ \mathrm{C} C}$ na água, valores que têm pouca influência nas possíveis alterações ao meio.

\section{CONCLUSÕES}

Conclui-se que apesar da coleta ser realizada em pleno inverno, a Lagoa Maior está com um nível de água tolerável e ainda recebendo águas pluviais armazenadas em algumas caixas de retenção construídas ao longo de sua margem, portanto, os contaminantes têm condições de diluição e assimilação.

Se pensarmos a Lagoa Maior como parte da drenagem do Córrego da Onça, é justamente na estação 10 onde a água da Lagoa escoa para o esse importante rio urbano que em sua foz encontra o Rio Paraná, e justamente na estação 10 o enquadramento e as limitações classificaram na classe I do CONAMA, resolução 357 de 2005. Podendo ser utilizada para "consumo humano, após tratamento simplificado; Proteção das comunidades aquáticas; Recreação de contato primário (natação, esqui aquático e mergulho), segundo a Resolução CONAMA n. 274, de 2000". O problema é que ao longo de seu percurso urbano, o Córrego da Onça é canalizado, recebendo esgoto clandestino 


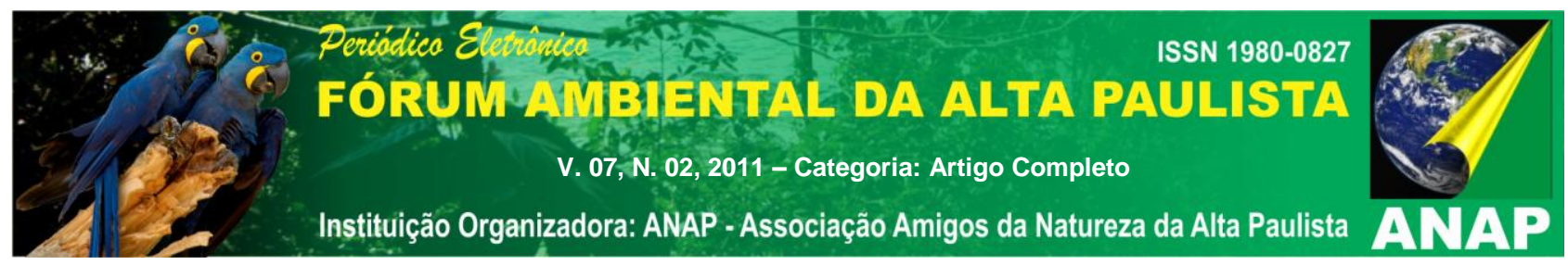

via galerias pluviais e na Vila Zucão, quando volta a correr a céu aberto, recebe grande deposição de resíduos sólidos e plumas de contaminações de fossas rudimentares.

Porém se forem considerados os resultados obtidos mais restritivos, em especial das caixas de retenção, como é o caso da estação 9, que devido à elevada turbidez de suas águas e de sua condutividade elétrica, tendo grande limitação de uso dessas águas que lançadas a lagoa Maior a contaminam.

Portanto, como trata-se de água destinada ao lazer e a recreação, ou fraciona-se as margens da Lagoa Maior e se estipula balneabilidade por trecho ou se considera como um corpo hídrico único e se utiliza o valor mais restritivo.

Valendo relembrar, que na estação seca do inverno, com menor entrada de água pluvial, as concentrações de OD e Condutividade Elétrica, tenderão a se elevar. Como o monitoramento com os parâmetros utilizados são de baixo custo e de fácil realização, propõem-se que sejam realizados mensalmente, para subsidiarem ações públicas sérias, em prol da saúde da coletividade urbana de Três Lagoas, que tem na Lagoa Maior um dos seus principais pontos de lazer e recreação.

\section{REFERÊNCIAS}

BOLLMANN, H. A.; CARNEIRO, C.; \& PEGORINI, E. S. Qualidade da água e dinâmica de nutrientes. In: ANDREOLI, C. V.; \& CARNEIRO, C. eds. Gestão integrada de mananciais de abastecimento eutrofizados. Editora Gráfica Capital. Curitiba, 2005, p.83-119.

BRASIL Conselho Nacional do Meio Ambiente - CONAMA Resolução 357/2005, Enquadramento dos Corpos Hídricos Superficiais no Brasil. Governo Federal, Brasilia. Publicada no DOU nํ53, de 18 de março de 2005, Seção 1, p. 58 - 63.

CETESB. Companhia de Tecnologia de Saneamento Básico. Guia de coleta e preservação de amostras de água. São Paulo, 1987. 150p. (Séries guias) 


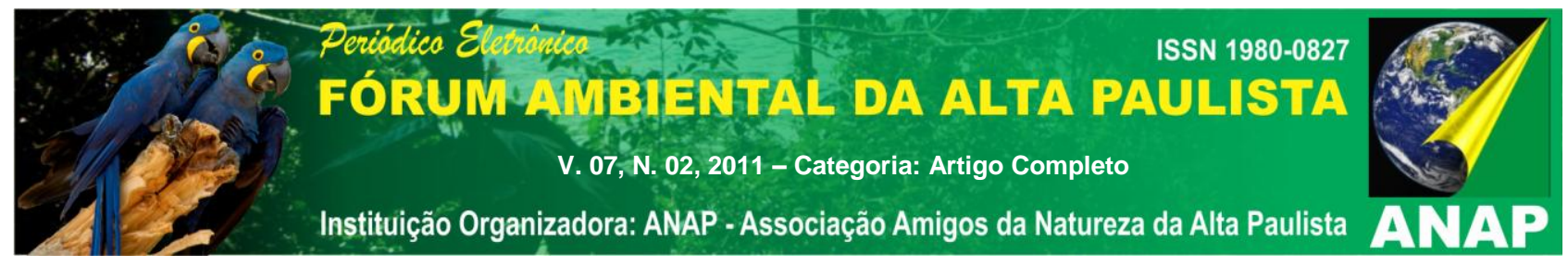

MOITTA, R.; CUDO, K. J. Aspectos gerais da qualidade da água no Brasil. In: Reunião Técnica sobre Qualidade da Água para Consumo Humano e Saúde no Brasil. Brasília, 1991, p. 1 - 6.

PINTO, A. L. Saneamento Básico e suas Implicações na Qualidade das Águas Subterrâneas da Cidade de Anastácio (MS). 1998. 175p. Tese (Doutorado e Geociências) - Universidade Estadual Paulista/Instituto de Geociências e Ciências Exatas, Rio Claro, 1998.

REBOUÇAS, A. Uso Inteligente da Água. Escrituras Editora. São Paulo, 2004. 207p.

SILVEIRA, M. P. Aplicação do biomonitoramento para avaliação da qualidade da água em rios. Embrapa Meio Ambiente. Jaguariúna, 2004.

TUCHOBANOGLOUS, G.; SCHROEDER, E. D. Water quality - characteristics, modelling, modfication. Addison-Wesley Publ. Co., EUA, 1985.

TUNDISI, J. G. Liminologia do século XXI: perspectivas e desafios. São Carlos: Suprema Gráfica e Editora, 1999. 24 p. 